\title{
Um Estudo Sobre Interpretações e Representações de Números Racionais em uma Escola Pública de Educação de Surdos em Santa Maria/RS
}

\section{A Study on Interpretations and Representations of Rational Numbers in a Public Education School of Deaf in Santa Maria/RS}

\author{
Tainara da Silva Guimarães ${ }^{\text {a; }}$ Rita de Cássia Pistóia Mariani*a \\ ${ }^{a}$ Universidade Federal de Santa Maria, Programa de Pós-Graduação Stricto Sensu em Educação Matemática. RS, Brasil. \\ *E-mail: rcpmariani@yahoo.com.br
}

\begin{abstract}
Resumo
O presente trabalho parte da seguinte questão: quais entendimentos são mobilizados por estudantes surdxs em tarefas sobre números racionais utilizando o material manipulável tangram? Diante disso, tem-se por objetivo analisar registros de representação semiótica mobilizados por estudantes surdxs do $1^{\circ}$ ano do Ensino Médio, em uma escola estadual bilíngue de Santa Maria/RS, considerando uma sequência de tarefas envolvendo números racionais nas interpretações parte-todo, medida e operador. Para tanto, caracteriza-se como uma pesquisa qualitativa na forma de um estudo de caso com produção de dados orientada pelos princípios da análise de conteúdo. Nessa perspectiva constitui-se quatro categorias: parte-todo, equivalência, medida e operador. Quanto a parte-todo constata-se que a partir da conversão da representação figural icônica para numérica fracionária, sua compreensão deu-se principalmente. Na equivalência de números racionais verifica-se a relevância de tratamentos figurais na representação icônica, por meio da mobilização de registros das peças do tangram. Em relação a medida conclui-se que houve compreensão no espaço unidimensional, ao identificar os números racionais correspondentes aos valores das áreas abordadas como a distância de um certo ponto até a origem na reta numérica, e no espaço bidimensional, a partir da medida da área de figuras. No operador, observa-se reduções de áreas de figuras geométricas quadradas, evidenciando tratamentos figurais na representação icônica. Por fim, destacase ampliação do repertório linguístico dxs estudantes referentes aos conceitos/conteúdos matemáticos, tendo em vista a convenções de sinais institucionalizados durante a dinamização da sequência.
\end{abstract}

Palavras-chave: Educação de Surdos. Ensino Médio. Tangram. Parte-Todo. Medida. Operador.

\begin{abstract}
The present paper starts from the following question: what understandings are mobilized by deaf students in tasks about rational numbers using the manipulable tangram material? Therefore, the objective is to analyze semiotic representation records mobilized by deaf students of the first year of high school, in a bilingual state school in Santa Maria/RS, considering a sequence of tasks involving rational numbers in the interpretations part-whole, measure and operator. For this purpose, it is characterized as a qualitative research in the form of a case study with data production guided by the principles of content analysis. From this perspective, four categories are constituted: part-whole, equivalence, measure and operator. As for the whole-part it is found that from the conversion of the iconic figural representation to fractional numerical, its understanding took place mainly. In the equivalence of rational numbers, the relevance of figurative treatments in iconic representation is verified through the mobilization of records of tangram pieces. With respect the measurement, it can be concluded that there was understanding in one-dimensional space, by identifying the rational numbers corresponding to the values of the approached areas as the distance from a certain point to the origin in the numerical line, and in two-dimensional space, from the measurement of the area of figures. In the operator, there are reductions in areas of square geometric figures, showing figurative treatments in the iconic representation. Finally, we highlight the expansion of the linguistic repertoire of students referring to mathematical concepts/contents, in view of the conventions of institutionalized signals during the dynamization of the sequence.
\end{abstract}

Keywords: Deaf Education. High School. Tangram. Part Whole. Measure. Operator.

\section{Introdução}

Atualmente, a educação de surdxs ${ }^{1}$ se desenvolve a partir da perspectiva visual/espacial, com objetivo de possibilitar o acesso aos conceitos/conteúdos na Língua Brasileira de Sinais (Libras), tendo como preocupação respeitar a autonomia desta língua e estruturar um plano educacional sem interferir na experiência psicossocial (Quadros, 1997). Deste modo, a educação bilíngue para surdxs, é caracterizada pela aquisição da Libras como primeira língua e do português, como língua secundária.

No Brasil, as discussões sobre a educação bilíngue para surdxs tiveram início no I Congresso Latino Americano de Educação Bilíngue para Surdos, realizado em 1995. Posteriormente, no V Congresso Latino Americano de Educação Bilíngue para Surdos, em 1999, a comunidade surda

\footnotetext{
1 Utilizamos a letra ' $x$ ' como uma desinência nominal de gênero, a fim de valorizar, com a linguagem, a atuação de pessoas com quaisquer que sejam as identidades sociais.
} 
organizou um pré-congresso entre educadorxs e lideranças da comunidade surda mundial (América Latina, América do Norte e Europa) visando sua mobilização política (Coutinho, 2015). Nesse congresso ocorreram debates envolvendo a comunidade surda enfatizando identidade surda, cultura e educação de surdxs, resultando no documento intitulado "A Educação que nós surdos queremos" (Feneis, 1999).

Este documento serviu como referência para a elaboração do decreto que regulamentou a Língua de Sinais - Lei da Libras no 10.436 (Brasil, 2002), e também para fundamentar a Política Nacional de Educação Especial na Perspectiva Inclusiva (Brasil, 2008), partindo de pressupostos sobre o direito a educação bilíngue, como espaço de resistência e edificação da identidade surda. Desta forma, entende-se que a presença da Libras em sala de aula foi definida como de responsabilidade de tradutorxs e de intérpretes da língua de sinais (TILS). O Decreto $n^{\circ} 5.626 / 05$ reitera que a função de tal profissional não pode ser confundida com a docente (Brasil, 2005).

Ainda, este decreto ressalta que a educação bilíngue deve ser desenvolvida por intermédio de docentes bilíngues (Brasil, 2005). O Relatório sobre a Política Linguística de Educação Bilíngue afirma que esta envolve a criação de ambientes linguísticos para a aquisição da Libras, tendo por objetivo garantir esta e a aprendizagem das línguas desenvolvidas, sendo necessárias para a educação de surdxs, construindo sua identidade linguística e cultural em Libras de modo igualitário as crianças ouvintes e falantes em português (Brasil, 2014).

A partir desse contexto social surge um paradigma educacional, em busca novas alternativas pedagógicas, com intuito de transformar o ambiente escolar, em especial, o ensino e aprendizagem de matemática. Na perspectiva visual/ espacial, Morgado, Santos e Takinaga (2016) enfatizam que, o ensino e a aprendizagem de matemática podem ser estimulados por meio da utilização de materiais didáticos manipuláveis dispondo dos sentidos (tato, olfato, paladar, visão e audição), servindo como instrumentos de apoio para qualquer estudante.

Nessa ótica, Lorenzato (2006) relata que, materiais didáticos podem ser utilizados para favorecer o ensino e a aprendizagem, sendo capaz de facilitar a compreensão de conceitos/conteúdos matemáticos. Em conformidade, pesquisas apontam que a utilização de materiais manipuláveis na educação de surdxs valorizam o estímulo visual destes sujeitxs (Lemes, 2014, Nascimento, 2014, Santos, 2015, Kipper, 2015), bem como a utilização de registros figurais (Souza, 2010) sendo pertinente trabalhar a parte visual (Silva, 2014).

De acordo com Neves (2011, p.112) “é necessário fazer um mergulho na perspectiva destes (sujeitos surdos), no seu jeito de ver o mundo e construir uma ponte em que resulte conhecimentos". Assim, o ensino de matemática deve ir além da utilização de simbologias, tornando necessário refletir sobre propostas e projetos pedagógicos que contemplem as habilidades dxs sujeitxs surdxs.

Com isso, entendemos que a utilização de materiais didáticos manipuláveis, pode abarcar a exploração de estímulos visuais em atividades matemáticas possibilitando o acesso aos sentidos de tato e visão, permitindo a sondagem de registros figurais. Neste viés, o presente trabalho parte da seguinte questão: quais entendimentos são mobilizados por estudantes surdxs em tarefas sobre números racionais utilizando o material manipulável tangram? A partir deste questionamento, objetivamos analisar registros de representação semiótica (Duval, 2003, 2011, 2012a, 2012b) mobilizados por estudantes surdxs do $1^{\circ}$ ano do Ensino Médio, em uma escola estadual bilíngue de Santa Maria/RS, considerando uma sequência de tarefas envolvendo números racionais nas interpretações parte-todo, medida e operador, segundo Lamon $(2007,2012)$.

Para tanto, tomamos o tangram (Figura 1) como material manipulável que pode ser definido como quebra-cabeça, formado por sete peças, sendo cinco triângulos com três tamanhos distintos, um quadrado e um paralelogramo. Considerando o quadrado formado pelas sete peças do tangram como unidade, podemos determinar as áreas das demais peças (Santos; Imenes, 1987), por exemplo, a área de $1 \mathrm{Tg}$ corresponde a, pois são necessários $4 \mathrm{Tg}$ para formar o quadrado unitário, ou seja, esta peça "cabe" quatro vezes inteiras neste quadrado e o preenche totalmente.

Figura 1 - Material manipulável tangram

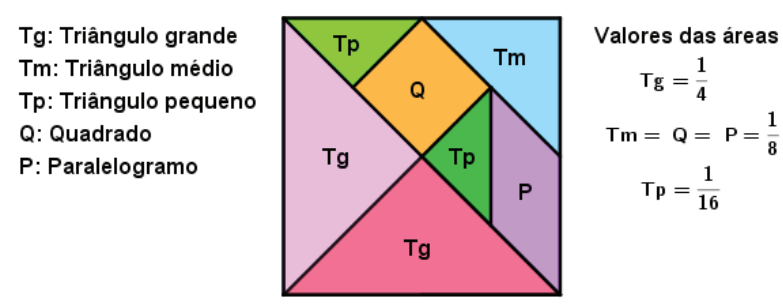

Fonte: Baseada em Santos \& Imenes (1987).

Com a finalidade de atingir nosso objetivo planejamos e desenvolvemos uma sequência composta por quatro tarefas envolvendo interpretações de números racionais, sendo partetodo (Tarefa 1 e 2), medida (Tarefa 3 ) e operador (Tarefa 4), em uma turma de $1^{\circ}$ ano do Ensino Médio, usando o tangram como material manipulável. Além da proposta de Santos \& Imenes (1987), mencionada anteriormente, tal sequência foi baseada nos trabalhos de Souza (2016) e Guimarães (2017).

Para compor o respectivo trabalho estruturamos seis seções. Inicialmente, apresentamos o referencial teórico, em seguida caracterizamos o campo da pesquisa, também exibimos e analisamos o desenvolvimento desta sequência e ao fim tecemos algumas considerações a respeito de nossa pesquisa.

\section{Ensino e Aprendizagem de Números Racionais}

Para além das críticas pertinentes expostas durante a 
constituição e homologação da Base Nacional Comum Curricular - BNCC (Brasil, 2018b), consideramos que é necessário compreender o que está posto neste documento, tendo em vista a intenção de que ela pretende determinar parte do currículo obrigatório do Brasil. No Ensino Fundamental a BNCC (Brasil, 2018b), considera para a Matemática habilidades organizadas conforme unidades de conhecimento (Números, Álgebra, Geometria, Grandezas e Medidas, Probabilidade e Estatística). Em relação aos Números, propõe-se o desenvolvimento de habilidades referentes ao pensamento numérico, com intuito de ampliar a compreensão de diferentes campos e significados das operações.

Para isso, sugere a resolução de problemas envolvendo os conjuntos numéricos (números naturais, inteiros, racionais e reais), em diferentes contextos (do cotidiano, da própria Matemática e de outras áreas do conhecimento). Além disso, indica que a partir do $4^{\circ}$ ano, a abordagem da representação fracionária unitária como partes de uma unidade e propõe a exploração da representação decimal, por meio do reconhecimento do sistema monetário brasileiro (Brasil, 2018a).

No $5^{\circ}$ ano, o ensino sobre a representação fracionária pode ser associado a ideia de divisão ou a parte de um todo. Enquanto, a abordagem da representação percentual é indicada como $10 \%, 50 \%$ e $100 \%$. No $6^{\circ}$ ano, propõe a ampliação do reconhecimento de números racionais positivos nas representações fracionária e decimal, a partir de relações entre essas, enfatizando a conversão de ambas e relacionando-as a pontos na reta numérica. No $7^{\circ}$ ano, recomenda a exploração dos significados/interpretações: parte de inteiros, resultado da divisão, razão, operador e a associação a pontos na reta numérica (Brasil, 2018a).

Sendo assim, durante o Ensino Fundamental tal documento aconselha o desenvolvimento do ensino de números racionais nas representações decimal, percentual e, principalmente, fracionária instigando os significados parte-todo e quociente, além da equivalência e da comparação. Para o Ensino Médio a área de Matemática e suas Tecnologias propõe a ampliação e o aprofundamento dos conceitos/conteúdos desenvolvidos até o $9^{\circ}$ ano do Ensino Fundamental, de modo a possibilitar uma visão mais integrada da Matemática para estudantes, ainda na perspectiva de sua aplicação à realidade (Brasil, 2018b).

Em vista disso, associamos os significados propostos pelo documento supracitado como sendo as interpretações de números racionais, propostas por Lamon (2007; 2012), e o desenvolvimento de suas representações por meio dos registros de representações semióticas de Duval (2003, 2011, 2012a, 2012b).

\section{Interpretações e representações de números racionais}

Os números racionais são um dos temas mais complexos de ensinar e essencial para o desenvolvimento da matemática superior e da ciência e tais dificuldades podem estar associadas a rupturas nos entendimentos sobre números naturais (Lamon,
2007). A autora ainda expõe que os números racionais podem ser interpretados de cinco maneiras: parte-todo, medida, operador, quociente e razão.

A interpretação parte-todo desenvolve-se por meio de partições congruentes de uma unidade, onde as partes divididas indicam o denominador $\mathrm{e}$ as consideradas $\mathrm{o}$ numerador (Lamon, 2012). Vale destacar que uma unidade pode ser formada por mais de uma parte e números racionais em representações diferentes podem representar a mesma quantidade, envolvendo a equivalência (Lamon, 2007).

A interpretação medida de números racionais está relacionada à medida atribuída a um intervalo, no espaço unidimensional, ou a região, no espaço bidimensional (Lamon, 2012). Desta maneira, no espaço unidimensional, o número racional está relacionado a medida da distância de um certo ponto até a origem na reta numérica e, no espaço bidimensional, um número racional mede a área de uma determinada região.

As atividades que envolvem a interpretação operador podem ser compreendidas como uma modificação de certa quantidade. Lamon (2012) define esta interpretação como sendo a transformação que ocorre sobre um número ou uma quantidade, ampliando-o ou reduzindo-o, isto é, funciona como uma máquina que aumenta e diminui, mantendo suas características. Também pode ser abordada a partir de composições, sendo possível a realização de diferentes operações sob determinado resultado.

Quanto a interpretação quociente é considerada base para a compreensão de números racionais e está diretamente relacionada a operação de divisão (Lamon, 2012). Desta forma, a principal característica das atividades que requerem a intepretação quociente é a possibilidade de ser usada para representar a operação, ou seja, é possível indicar esta divisão pelo número racional .

A última interpretação apresentada por Lamon (2007) é a razão. Essa interpretação está associada à representação de uma relação na forma "a:b" ou "a está para b". Definida como comparação de quaisquer duas quantidades que constituem o todo e se modificam, mas mantem sua proporção, podendo ser utilizada para comunicar uma ideia que não pode ser explanada como um único número (Lamon, 2012).

Entre as cinco interpretações de números racionais organizadas por Lamon (2007, 2012), nesta pesquisa, optamos por enfatizar parte-todo, medida e operador na sequência de tarefas. Tendo em vista a aproximação do modo de abordagem dos documentos orientadores do ensino supracitados, consideramos mais adequadas e propomos uma abordagem explorando as diferentes representações semióticas de números racionais.

Duval (2012b) afirma que existem três atividades cognitivas fundamentais dos registros de representação, são elas formação, tratamento e conversão. A formação está relacionada ao processo de produção e internalização de uma representação, envolve a constituição de traços perceptíveis 
uteis para identificar ou representar algo.

Ao combinar sinais em Libras estudantes surdxs formam atos elementares da atividade cognitiva de formação para cada representação (Frizzarini, 2014). Por isso, consideramos a Libras como sendo uma representação discursiva, embasada nas categorias previstas por Duval (2011). As duas outras atividades cognitivas são ditas transformações. A conversão é uma transformação externa, onde a representação é transformada em outra representação num sistema representacional diferente (Duval, 2012b). O tratamento é uma transformação interna, em que a representação é modificada tornando-se outra dentro do mesmo sistema representacional.

As representações podem ser classificadas como discursivas e não-discursivas. Sendo a primeira, supracitada, na representação em língua natural, no registro simbólico numérica fracionária, decimal ou percentual, e no registro algébrico. Enquanto as não-discursivas podem ser no registro figural nas representações icônica e/ou geométrica.

Cabe explicitar com mais detalhes informações sobre o registro figural, que não é o material manipulável tangram, mas que pode ser desencadeado por ele na medida em que são realizadas anotações em protocolos. Duval (2012a) define tratamentos figurais como sendo processos realizados em unidades figurais, em uma figura geométrica, materialmente ou mentalmente. Com efeito, temos as apreensões geométricas: perceptiva, sequencial, discursiva e operatória.

A apreensão perceptiva consiste em reconhecer e interpretar os elementos figurais de uma figura, por exemplo, contornos e formas (Duval, 2012a). A apreensão sequencial engloba a construção geométrica da figura considerando suas propriedades, como, por exemplo, as medidas dos ângulos internos para construir um retângulo (Duval, 2012b).

A apreensão discursiva envolve a interpretação das unidades figurais - dimensionais e qualitativa - articulada com o enunciado, ou seja, relacionar e compreender o enunciado com a figura exposta na atividade (Duval, 2012a, 2012b). A apreensão operatória abrange possíveis modificações figurais e a reorganização da figura, por exemplo, particionar $1 \mathrm{Tm}$ em 2 Tp (Duval, 2012a; 2012b). Tais modificações podem ser caracterizadas por Duval (2012a) como mereológica, ótica e posicional.

A modificação mereológica está relacionada a partição de uma figura em várias subfiguras, havendo a possibilidade de incluir uma figura dentro da outra tornando-a uma subfigura. A modificação ótica implica na alteração de uma figura por meio da ampliação, diminuição ou, até mesmo, deformação sendo capaz de transformar em outra. Por fim, a modificação posicional referente a mudança de posição da figura, a partir da rotação e da reflexão com relação ao eixo de referência.

\section{Encaminhamentos Metodológicos}

O presente trabalho caracteriza-se como pesquisa qualitativa na forma de um estudo de caso, pois dispomos do contato das pesquisadoras com o ambiente e a situação investigada, tendo os dados produzidos, majoritariamente, de forma descritiva, promovendo a comparação entre dados, evidências, informações produzidas e conhecimento teórico (Lüdke \& André, 1986).

Para analisar a sequência de tarefas optou-se pela organização da análise de conteúdo de Bardin (1977), caracterizando-se por três polos cronológicos, ou seja, préanálise; exploração do material; e tratamento dos resultados, inferência e interpretação.

A pré-análise é a fase de organização, tendo por objetivo sistematizar as ideias iniciais, conduzindo para um esquema preciso de seu desenvolvimento. Para isso desenvolvemos ações que contemplaram observações de aulas; planejamento e dinamização de uma Tarefa Exploratória contendo seis atividades sobre apropriação e manipulação do tangram, nomeação das peças do material, conceito/conteúdo de unidade de área, interpretação parte-todo, interpretação medida e identificação do conjunto dos números racionais.

Para além disso, elaboramos e desenvolvemos um questionário semiestruturado com vinte e seis perguntas com diferentes enfoques, a saber: Um pouco sobre você, Um pouco de sua experiência com a LIBRAS, Um pouco da sua formação escolar. Por meio desse instrumento elaboramos o perfil dxs estudantes participantes do estudo matriculadxs no $1^{\circ}$ ano do Ensino Médio da Escola Estadual de Educação Especial Dr. Reinaldo Fernando Cóser (EEEERFC). Para encerrar a préanálise estruturamos a sequência composta por quatro tarefas totalizando trinta e duas atividades.

A segunda fase, isto é, a exploração do material consiste essencialmente nas operações de codificação, a qual permite a dinamização dos instrumentos de produção de dados, bem como realização das primeiras análises. Para a análise da sequência, organizarmos quatro categorias a priori, cada uma vinculada a uma das tarefas: parte-todo (Tarefa 1), equivalência (Tarefa 2), medida (Tarefa 3 ) e operador (Tarefa 4).

Na última fase são realizados e apresentados o tratamento dos resultados e as interferências. O tratamento de resultados permite estabelecer quadros, modelos e figuras, diagramas através da condensação dos dados obtidos (Bardin, 1977)².

\subsection{Um Pouco Sobre o Campo de Pesquisa e o Desenvolvimento da Sequência de Tarefas}

No estado do Rio Grande Sul está concentrado o maior número de escolas específicas para surdxs do Brasil, pois existe 14 ao total (Beras \& Lunardi-Lazzarin, 2017). Atualmente, a maioria delas estão localizadas na região metropolitana de Porto Alegre, sendo apenas 4 no interior do estado. Entre estas temos a EEEERFC situada na região periférica do município de Santa Maria, atendendo estudantes de toda região.

2 Tal fase será explicitada, neste artigo, com mais detalhes na seção 6 . 
A instituição contempla Educação Infantil, Ensino Fundamental, Ensino Médio, Curso Normal (Magistério) e Educação de Jovens e Adultos, durante os três turnos. Tendo como metas constantes da proposta educacional da escola bilíngue: o reconhecimento da pessoa surda dentro da própria comunidade surda e a utilização da língua de sinais na escola, garantindo seu desenvolvimento cognitivo e o ensino de conhecimentos gerais (EEEERFC, 2018).

Desde nosso primeiro contato percebemos um ambiente acolhedor, espaços estruturados e planejados para e pela comunidade surda. Desde o som da sirene juntamente com a campainha luminosa, cartazes produzidos pelxs estudantes surdxs com a escrita em Libras expostos em salas de aulas e corredores, assim como uma obra de arte na faixada da escola, com a escrita em Libras combinada ao desenho de um olho, receptor de estímulos visuais, e de mãos, principal meio de comunicação.

Também, observamos integração entre pessoas surdas e ouvintes fluentes em Libras, tendo em vista docentes e funcionárixs ouvintes. Cabe mencionar que na instituição há estudantes surdxs com diferentes graus de surdez e alguns fazem uso de aparelho auditivo.

No ano letivo de 2018, ano em que desenvolvemos nossa pesquisa, a EEEERFC possuía setenta e seis estudantes surdxs regularmente matriculadxs, entre estes dezesseis cursavam o Ensino Médio, tendo duas turmas de $2^{\circ}$ ano e uma de $1^{\circ}$ ano. A turma do $1^{\circ}$ ano era composta por 7 estudantes matriculadxs e 5 estudantes frequentes. Para preservar a identidade de cada participante atendendo os preceitos do CEP/UFSM ${ }^{3}$, lhes foram designados nomes fictícios definidos por cada estudante, conforme evidencia o Quadro 1.

Quadro 1 - Perfil de participantes

\begin{tabular}{|c|c|c|c|c|}
\hline $\begin{array}{c}\text { Nome } \\
\text { fictício }\end{array}$ & $\begin{array}{c}\text { Grau de } \\
\text { surdez }\end{array}$ & Comunicação & Idade & $\begin{array}{c}\text { Identidade } \\
\text { de gênero }\end{array}$ \\
\hline Cris & Profunda & Em LIBRAS & 20 & Feminina \\
\hline Gabi & Leve & $\begin{array}{c}\text { Oralmente e } \\
\text { em LIBRAS }\end{array}$ & 17 & Feminina \\
\hline Japapaty & Severa & Em LIBRAS & 22 & Masculina \\
\hline Camily & Severa & $\begin{array}{c}\text { Oralmente e } \\
\text { em LIBRAS }\end{array}$ & 18 & Feminina \\
\hline Stifinhy & Severa & Em LIBRAS & 16 & Feminina \\
\hline
\end{tabular}

Fonte: Dados da pesquisa.

Com relação ao grau de surdez podemos observar que três participantes possuem surdez severa, ou seja, nenhum som de fala é audível em nível de conversação natural, conseguindo ouvir apenas sons como o latido de cães. Uma estudante com o grau de surdez profunda com a possibilidade de nenhum som ser entendido, provocando dificuldade na aquisição da fala, e outra com surdez leve, assim pode ouvir o som das vogais e de algumas consoantes. Ademais, percebemos que há uma variação de idade destes entre 16 e 22 anos, não condizendo com a idade esperada para o $1^{\circ}$ ano do Ensino Médio.
Ainda constatamos outras características, por exemplo, em relação ao deslocamento até o local escolar e a realização de trabalhos extracurriculares, pois Cris e Camily residem na cidade de Tupanciretã, percorrendo diariamente cerca de 100 $\mathrm{km}$ até o ambiente escolar, por este motivo não se fizeram presentes no desenvolvimento de todas as tarefas. Gabi realiza trabalhos extracurriculares, como cuidar de criações de animais e trabalho doméstico, fora do horário escolar, o que também dificultou sua presença no desenvolvimento da sequência de tarefas.

$\mathrm{O}$ desenvolvimento da sequência de tarefas ocorreu em quatro encontros entre o final do mês de novembro e início de dezembro de 2018, no horário regular das aulas (Quadro 2). Para que fosse possível desenvolver a pesquisa em $2 \mathrm{~h} / \mathrm{a}$ seguidas, utilizamos períodos da aula de Matemática e de outras disciplinas, reorganizados e disponibilizados pela EEEERFC.

Quadro 2 - Desenvolvimento da sequência de tarefas

\begin{tabular}{|c|c|c|c|c|c|}
\hline & Data: & $\begin{array}{l}26 / 11 \\
/ 2018 \\
\end{array}$ & $\begin{array}{l}28 / 11 \\
/ 2018 \\
\end{array}$ & $\begin{array}{l}30 / 11 \\
/ 2018 \\
\end{array}$ & $\begin{array}{l}05 / 12 \\
/ 2018 \\
\end{array}$ \\
\hline \multirow{5}{*}{$\begin{array}{c}\text { Estudantes } \\
\text { presentes }\end{array}$} & Cris & घ & & a & \\
\hline & Japapaty & - & - & - & घ \\
\hline & Stifinhy & $\square$ & - & $\square$ & $\square$ \\
\hline & Camily & $\square$ & & $\square$ & \\
\hline & Gabi & - & & $\square$ & - \\
\hline
\end{tabular}

Fonte: As autoras.

Para efetivar este trabalho contamos com o apoio de uma intérprete, para traduzir os enunciados e auxiliar na comunicação das pesquisadoras e estudantes, e de três colaboradoras, que efetuaram gravações em vídeo tornando possível a realização da análise dos sinais convencionados, além dos registros de representação semiótica mobilizados. No total tivemos quarenta e nove vídeos gravados com um tempo total de 8 horas e 10 minutos.

Durante o desenrolar da sequência de tarefas a intérprete ficou posicionada em frente a turma, próxima ao meio, de modo que todxs pudessem vê-la, para observarem a tradução de cada atividade da tarefa. As colaboradoras, afim de efetuar as filmagens em vídeos, foram posicionadas ao lado mais a frente dxs estudantes. Para além das gravações de vídeos, também analisamos protocolos dxs cinco estudantes surdxs do $1^{\circ}$ ano do Ensino Médio. Vale destacar que organizamos a turma em duplas e/ou trio, sempre que possível, com intuito de provocar discussões a respeito das tarefas.

\subsection{A Sequência de Tarefas}

A Tarefa 1 (Figura 2), composta por quinze atividades, teve como objetivo mobilizar a interpretação parte-todo por meio de números racionais na representação fracionária com a exploração do conceito de área em peças triangulares do tangram. Sendo assim abordou esta interpretação a partir da 
área de uma figura geométrica simples, neste caso triângulos, conhecida dxs estudantes, vindo de encontro com a proposta do estudo de números racionais de Silva e Almouloud (2018),

Lamon (2007; 2012) e Silva e Assis (2013).

Figura 2 - Tarefa 1 relacionada a interpretação parte-todo

1-a) Monte edesenhe um quadrado com todas as peças do Tangram.

Escreva dentro das figuras sua respectiva sigla: $\mathrm{Tg}, \mathrm{Tm}, \mathrm{Tp}, \mathrm{P}$ ou $\mathrm{Q}$.

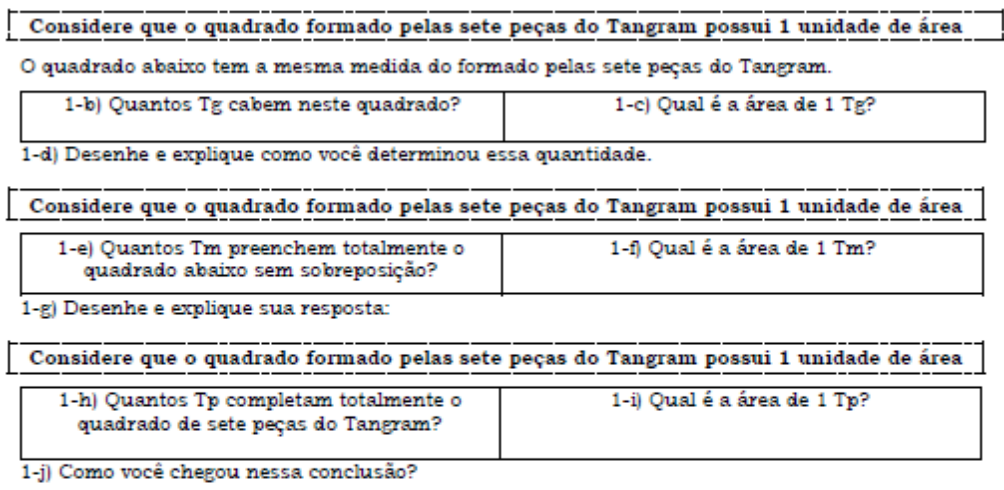

Considere que o quadrado de sete peças do Tangram foi dividi-do em 4 Triângulos Grandes (Tg) com os contornos abaixo.

\begin{tabular}{|c|c|}
\hline 1-k) Quantos Tm cabem em1 Tg? & 1-1) Quantos Tp cabem em1 Tg? \\
\hline $\begin{array}{c}\text { 1-m) Qual é a área preenchida pelos Tm } \\
\text { que você utilizou? }\end{array}$ & $\begin{array}{c}\text { 1-n) Qual é a área preenchida pelos Tp } \\
\text { que você utilizou? }\end{array}$ \\
\hline \multicolumn{2}{|c|}{ 1-o) Qual(is) outro(s) valor(es) pode(m) representar esta(s) área(s)? } \\
\hline
\end{tabular}

Fonte: As autoras.

Esta tarefa englobou a ideia conceitual de área (1-a), considerando o quadrado formado por todas as peças do tangram como uma unidade de área, visando a mobilização de números racionais a partir da área das peças triangulares (1-b, 1-c, 1-d, 1-e, 1-f, 1-g, 1-h, 1-i, 1-j). Também, buscou explorar sobre o conhecimento da ideia de equivalência de áreas das peças triangulares correspondentes a números racionais em sua representação fracionária (1-k, 1-1, 1-m, 1-n, 1-o), que seria enfatizada na próxima tarefa.

Além disso, abrange a compreensão de números racionais em sua representação fracionária como partes de uma unidade, desenvolvendo a identificação e associação da divisão ou como parte do todo (BNCC, 2018). Para isso, tem como partida o registro figural na representação icônica considerando as habilidades dxs estudantes, sendo a visual/ espacial, visando a mobilização de tratamentos figurais e a conversão da representação figural icônica para numérica fracionária.

A Tarefa 2 (Figura 3), constituída por cinco atividades, teve o intuito de mobilizar a interpretação parte-todo a partir de números racionais em sua representação fracionária com a exploração de equivalência de áreas entre as peças do tangram.

Figura 3 - Tarefa 2 relacionada a equivalência de números racionais

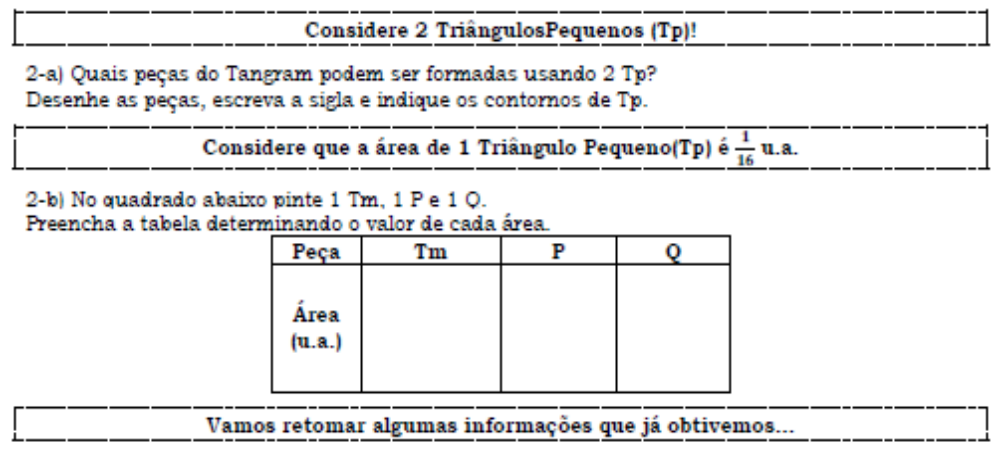

2-c) Escreva o valor da área de cada peça do Tangram:

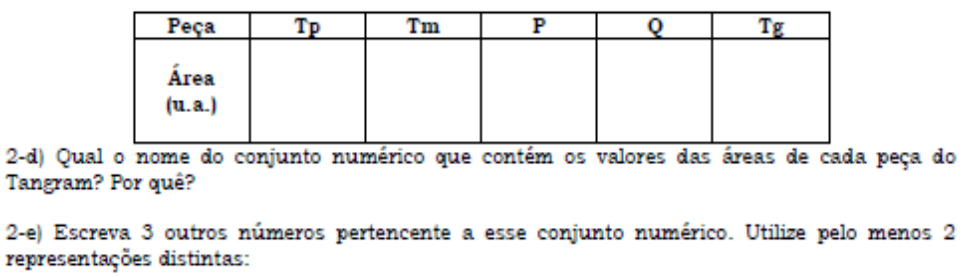

Fonte: As autoras. 
De acordo com Campos e Silva (2009), em sua pesquisa realizada com docentes, o tangram permite o desenvolvimento de situações problematizadoras acerca da equivalência, envolvendo a parte-todo por meio da conservação de áreas. Além disso, é possível analisar a equivalência por meio da percepção, ao dividir a área da figura em partes iguais (Campos, Magina \& Nunes, 2006; Lamon, 2012). Em resumo, enfatizou a equivalência das peças que não foram abordadas na Tarefa 1, isto é, Q e P, por se tratarem de figuras que podem ser decompostas em 2 Tp (2-a, 2-b). Também envolveu a identificação dos valores das áreas de todas as peças do tangram relacionando ao conjunto numérico (2-c, 2-d) e buscou instigar a mobilização de diferentes representações de números racionais (2-e), além da fracionária.

Neste viés, a compreensão sobre a interpretação partetodo ocorreu a partir da conversão da representação figural icônica para numérica fracionária, envolvendo a equivalência, de modo semelhante a Tarefa 1. Por outro lado, na Tarefa 2 evidenciamos a ideia de equivalência em relação a , comparando valores de áreas de figuras geométricas diferentes. Nesse sentido, promove a comparação entre partes do todo para obter as áreas das peças 1 Q, 1 P e 1 Tm em relação a 2 Tp (2-b).

A Tarefa 3 (Figura 4), organizada em seis atividades, objetivou mobilizar a interpretação medida a partir de números racionais no registro figural na representação geométrica e icônica por meio de áreas das peças do tangram. Cabe mencionar que a medida é um fator determinante na compreensão de números racionais, bem como ao entender as relações multiplicativas (Guerreiro, Serrazina \& Ponte, 2018; Guimarães \& Mariani, 2018; Lamon, 2007).

Figura 4 - Tarefa 3 referente a interpretação medida

$\begin{array}{r}\text { Para realizar esta tarefa relembre os valores das áreas de } \mathrm{T} p, \mathrm{Tm}, \mathrm{T}, \mathrm{P} \text { e } \mathrm{Q} \text { determinada na } \\ \text { atividade } 2-\mathrm{c} \text {. }\end{array}$

3-a) Indique os valores das áreas de cada peça do Tangram no segmento de reta abaixo.

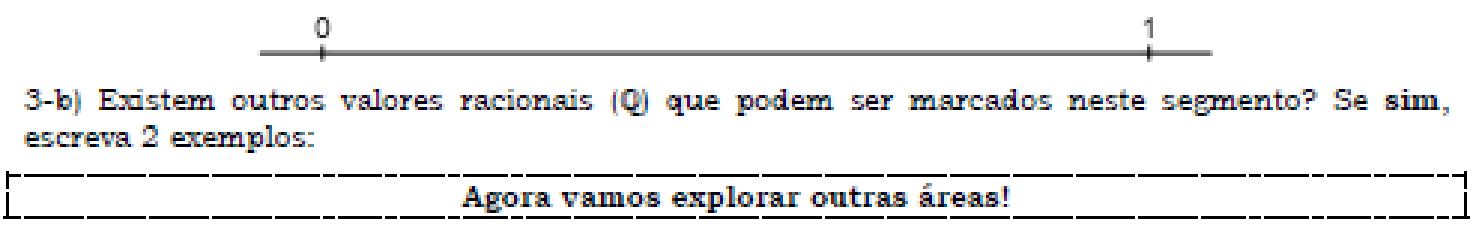

3-c) Preencha totalmente a Figura $1 \mathrm{com}$ as peças do Tangram desenhando seus contornos. Figura 1:

3-d) Qual é o valor da área da Figura 1?

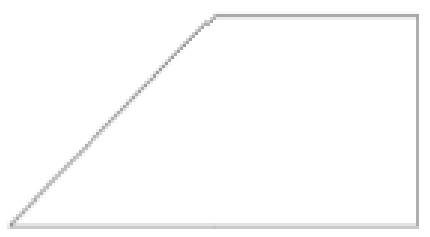

\section{DESAFIO}

3-e) Desenhe uma figura com as peças do Tangram em que a área seja maior que 0,25 u.a. (área de $\mathrm{Tg}$ ) e menor que 0,75 u.a (área da Figura 1).

3-f) No segmento de reta abaixo indique o valor da área da figura que você desenhou em 3-e.

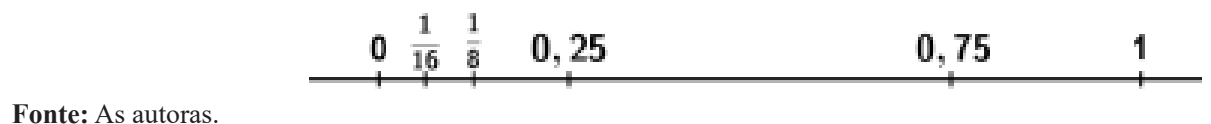

Fonte: As autoras.

Nesta tarefa, exploramos o espaço unidimensional, como distância de um certo ponto até a origem na reta numérica (3-a, 3-b), a partir do registro figural na representação geométrica, e bidimensional, medindo a área da figura (3-c, 3-d), partindo da representação figural icônica. Com a finalidade de desencadear a próxima tarefa, buscamos a abordagem da representação decimal de números racionais (3-e, 3-f), sugerindo a efetivação da mobilização de outra representação numérica além da fracionária, visando também a conversão entre a representação fracionária e a decimal.

A Tarefa 4 (Figura 5), constituída por seis atividades, teve intuito de mobilizar a interpretação operador a partir de números racionais nas representações fracionária, decimal e percentual por meio de transformações de áreas de quadrados formados com as peças do tangram. O operador está vinculado a operação de multiplicação e, sem dúvida, tem extrema importância no desenvolvimento do raciocínio multiplicativo (Moreira \& Ferreira, 2008; Lamon, 2012; Soares, 2016). 
Figura 5 - Tarefa 4 envolvendo a interpretação operador

Considere que o quadrado de sete peças do Tangram possui 1 unidade de área (u.a.)

4-a) Forme um quadrado que tenha $50 \%$ da área do quadrado de sete peças.

Desenhe abaixo o quadrado construído indicando os contornos das peças utilizadas:

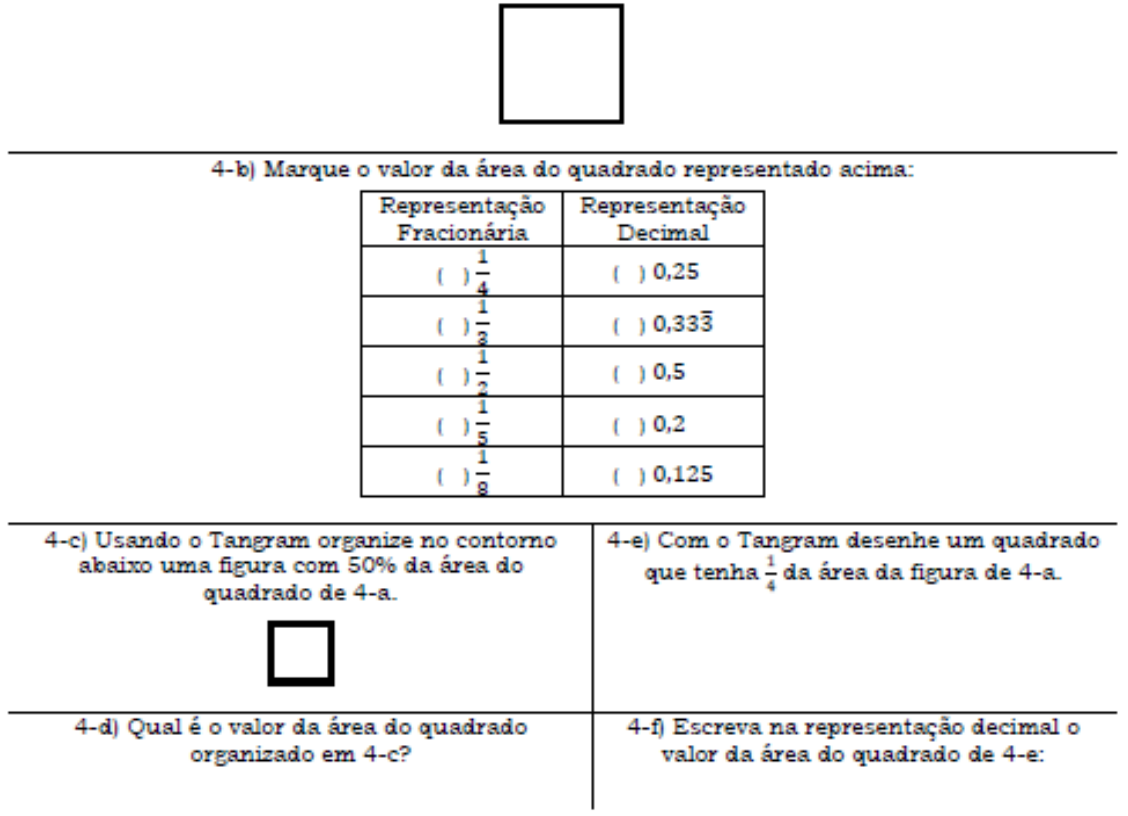

Fonte: As autoras.

Diante do exposto, abordou reduções de áreas do quadrado unitário formado por todas as peças do tangram (4-a, 4-b), e, por fim, cinquenta por cento (4-c, 4-d) e (4-e, 4-f) da área do quadrado reduzido incialmente. Ainda, vale destacar que, nesta tarefa, abordamos as conversões das diferentes representações numéricas, ou seja, fracionária, decimal e percentual.

Afim de explicitar, expor os resultados e tratamentos efetuados no desenvolvimento da sequência de tarefas, na seção seguinte descrevemos com mais detalhes como o mesmo ocorreu.

\section{Análise de Resultados, Tratamentos e Interpretações de Dados}

$\mathrm{Na}$ categoria parte-todo, constatamos que a partir da conversão da representação figural icônica para numérica fracionária ocorreu a compreensão da mesma. Inicialmente, para realizar o particionamento da representação figural icônica Camily sobrepôs $1 \mathrm{Tg}$ na figura e após particionou utilizando a régua, enquanto Stifinhy usou $4 \mathrm{Tg}$, Gabi concluiu que caberiam $4 \mathrm{Tg}$ sem usar as peças do tangram e também fez a divisão da figura com o auxílio da régua (1-b), destacamos que as alunas supracitadas realizaram esta tarefa em trio. Em relação a dupla, Cris e Japapaty, não se detiveram as peças do material, pois Cris sobrepôs $2 \mathrm{Tg}$ na figura e Japapaty ao observar este processo particionou utilizando apenas a régua (1-b). De maneira semelhante realizaram as demais atividades.

Deste modo, constatamos que houve compreensão por meio de tratamentos figurais na representação icônica, diretamente relacionado com a apreensão operatória mereológica, ao particionar o quadrado formado pelas sete peças do tangram em triângulos congruentes (1-d, 1-g, 1-j). Pelo viés dos tratamentos figurais e da organização perceptiva de uma figura relacionada a visibilidade percebemos indícios da apreensão sequencial, ao constituir figuras geométricas a partir de outras com o material manipulável tangram, neste caso, ao construir triângulos congruentes no interior do quadrado de sete peças (1-d, 1-g, 1-j).

Quanto a conversão da representação figural icônica para a numérica fracionária, Camily e Stifinhy constataram que o todo era formado pelas quatro peças de Tg e se escolhia uma delas obtinha-se, sendo este o valor correspondente a área de $1 \mathrm{Tg}$ (1-c). Enquanto Gabi precisou do auxílio da intérprete e das pesquisadoras para compreender que o todo ao ser particionado em quatro partes representava, assim se fosse escolhidas três partes deste todo teríamos, até concluir (1-c).

Já Japapaty concluiu o valor numérico referente a área de $1 \mathrm{Tg}$ após a sinalização da intérprete, ao mencionar a figura com o todo formado por $4 \mathrm{Tg}$ (1-c). Nesta situação, cabe mencionar que depois de compreender a atividade, Japapaty se dispôs a explicar para Cris, ocorrendo assim discussões das atividades.

Com isso, ao reconhecer o valor numérico racional correspondente a área das peças triangulares do tangram, abrangemos a interpretação parte-todo de números racionais na representação fracionária com o numerador igual a um (1-c, 1-f, 1-i). Tendo em vista as justificativas apresentadas pela turma em 1-d, 1-g, 1-j, a segurança e a facilidade, após entender a tradução do enunciado e a relação com a representação figural icônica, percebemos evidências das apreensões discursiva e perceptiva de formas. 
No âmbito da educação bilíngue, para efetuar as atividades várias vezes foi preciso retomar o quantitativo de partições da figura geométrica quadrado, ou seja, o número total de divisões do todo, principalmente em 1-k, 1-1, havendo a demanda de convencionar um sinal envolvendo esta ideia. Desta maneira, identificamos o sinal da palavra "total" como alternativa para sinalizar este conceito relacionando de maneira explicita a atividade de formação (Figura 6).

Figura 6 - Sinal da palavra "total" em Libras relacionado a interpretação parte-todo
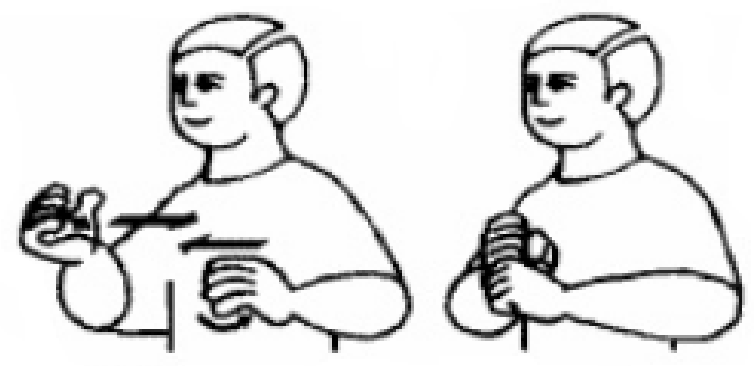

Fonte: Capovilla \& Raphael (2008).

$\mathrm{Na}$ categoria equivalência de números racionais, Tarefa 2 , desenvolveu-se a decomposição de áreas das peças do tangram em outras peças, isto é, $1 \mathrm{Q}, 1 \mathrm{P}$ e $1 \mathrm{Tm}$ seccionados em 2 Tp (2-b). Para compreender esta interpretação utilizamos o registro figural na representação icônica do quadrado unitário, formado por todas as peças do tangram, particionado em 16 $\mathrm{Tp}$, indicando o denominador. Para destacar o numerador, desse todo de 16 partes, solicitamos a pintura das peças $1 \mathrm{Tm}$, 1 P e 1 Q, sendo as partes consideradas.

Em princípio, Japapaty efetuou a leitura do português escrito de modo autônomo e construiu Q e P, sem o auxílio das pesquisadoras (2-a). Para realizar a decomposição de 1 Tm em 2 Tp, Japapaty precisou do auxílio das pesquisadoras, pois apresentou dificuldades ao sobrepor e posicionar $1 \mathrm{Tp}$. Enquanto isso, Stifinhy sobrepôs 2 Tp sobre as demais peças do tangram concluindo que não era possível construir somente a peças Tg com $2 \mathrm{Tp}(2-\mathrm{a})$.

Para mobilizar a representação figural icônica Stifinhy utilizou as peças Tm, Q e P e para dividir estas figuras usou 1 Tp. Já Japapaty para mobilizar a representação figural icônica de P usou 2 Tp e para particionar ocupou 1 Tp. Diante disso, houve a realização de tratamentos figurais na representação figural icônica ao estruturar 1 Q e 1 P por meio das peças do tangram, propiciando a mobilização das apreensões operatória mereológica e posicional (2-a).

$\mathrm{Na}$ atividade 2-b, Japapaty e Stifinhy posicionaram as peças e reconheceram os valores numéricos referentes as áreas de maneira semelhante, ambxs com o auxílio das pesquisadoras. Vale destacar que Stifinhy realizou a sobreposição e identificou Tm na figura, porém apresentou dificuldades ao posicionar $\mathrm{P}$, sendo preciso fazer a reflexão deste. Ao posicionar Q Stifinhy precisou gerar a peça em $90^{\circ}$ e observou quatro possibilidades de encaixe na figura.
Cabe destacar que apenas Japapaty identificou o valor numérico correspondente a área de $1 \mathrm{Tm}$ sendo, reconhecendo a equivalência entre os valores numéricos obtidos em 2-b, mobilizando tratamentos numéricos na representação fracionária. Já Stifinhy mobilizou todos os números racionais na representação fracionária correspondentes a área de $1 \mathrm{Tm}$, $1 \mathrm{Q}$ e 1 P como (2-c). Sendo assim ocorreu a conversão da representação figural icônica para a numérica fracionária em 2-b e também as apreensões perceptivas de formas e discursiva foram mobilizadas ao identificar as áreas de 1 P, 1 Q e 1 Tm na figura particionada em 16 Tp e ao relacionar a tradução do enunciado em 2-b.

No contexto da educação bilíngue tornou-se necessário convencionar um sinal para a palavra "equivalente", estabelecido pela intérprete. Sendo o sinal em Libras indicado para a palavra "equilíbrio" (Figura 7), não o encontramos em referências bibliográficas, como Capovilla \& Raphael (2008).

Figura 7 - Sinal da palavra "equilíbrio" em Libras convencionado para a equivalência

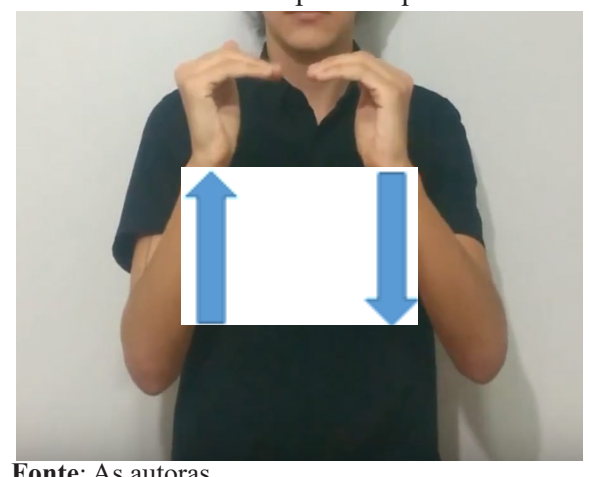

Fonte: As autoras.

Em relação a categoria medida, Tarefa 3, podemos concluir que sua compreensão se sucedeu no espaço unidimensional, ao compreender os números racionais correspondentes aos valores das áreas abordadas como a distância de um certo ponto até a origem na reta numérica (3-a). Camily localizou, incialmente, ao invés de, após a intervenção das pesquisadoras explicitando a consideração de apenas uma parte das oito divisões do segmento, esta compreendeu e marcou. Também realizou a mesma ideia para demarcar, após explicou para Stifinhy que a fez de modo análogo.

Entretanto, Stifinhy confundiu-se ao mobilizar a representação numérica fracionária trocando o numerador e o denominador. Já Gabi efetuou as demarcações de modo similar, porém não marcou (3-a). Quanto a Cris demarcou todos os valores numéricos racionais no segmento de reta, incluindo a marcação de duas vezes no mesmo ponto por corresponder ao valor de duas áreas de peças distintas do material (3-a). Nesta conjuntura, houve mobilização da conversão da representação numérica fracionária para a geométrica no registro figural, bem como da apreensão operatória mereológica, ao dividir o segmento com comprimento equivalente para demarcar o ponto.

Quanto ao reconhecimento da interpretação medida de 
números racionais no espaço bidimensional, desenvolveuse a partir da medida da área de figuras geométricas (3-b). Deste modo, constamos as operações figurais por meio da mobilização das apreensões operatória mereológica e posicional com indícios da sequencial (3-e), ao construir uma figura geométrica com área entre $\mathrm{e}$, utilizando as peças do tangram. Também, destacamos a conversão da representação decimal para a fracionária realizada pela Stifinhy, Camily e Gabi em 3-f, ao associar ao valor da área de 1 Tg, e o equívoco cometido por Cris ao demarcar na representação numérica fracionária a área de $1 \mathrm{Tg}$.

No decorrer da tarefa, dois sinais foram mais enfatizados, são eles: o sinal para a palavra "medida", ao mencionarmos as partições da representação geométrica com o mesmo comprimento, diretamente relacionado a interpretação medida e o sinal para a palavra "divisão", ao realizar a operação matemática (Figura 8).

Figura 8 - Sinais mobilizados na Tarefa 3

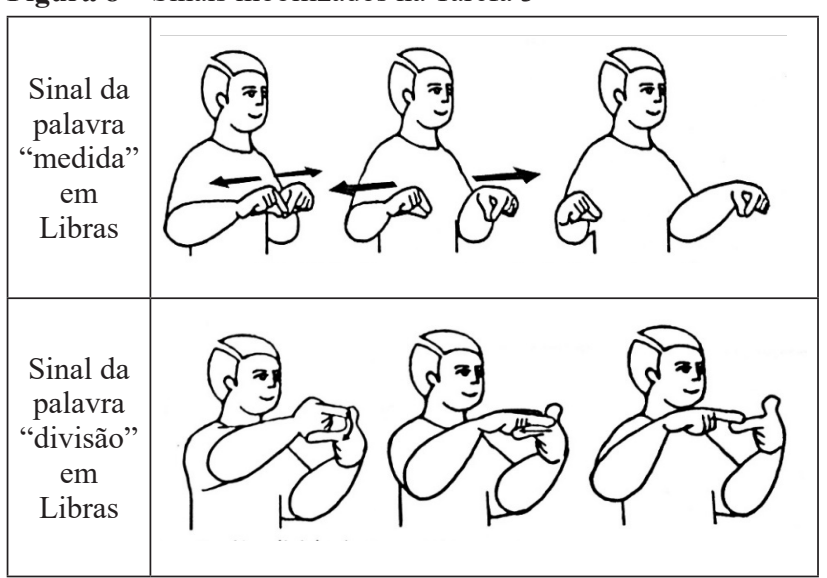

Fonte: Capovilla \& Raphael (2008).

$\mathrm{Na}$ última categoria operador, Tarefa 4, concluímos a compreensão mediante a redução de áreas de figuras geométricas quadradas, evidenciando tratamentos no registro figural na representação icônica utilizando as peças do tangram (4-a, 4-c, 4-e). Gabi intuitivamente preencheu a representação figural icônica com peças do tangram, logo formou um quadrado com 2 Tg e mostrou para Stifinhy e Japapaty.

No entanto, não havia ocorrido a compreensão da redução da área. Assim retomamos a construção do quadrado unitário com todas as peças do tangram e explicamos que era preciso reduzir sua área na metade (2-a). Após a explicação Japapaty dividiu o quadrado em duas partes e estruturou com 2 Tg um novo quadrado com a área reduzida.

Para mobilizar a representação figural icônica, Japapaty utilizou as peças do tangram, Stifinhy preencheu a figura com $2 \mathrm{Tg}$ e particionou usando a régua e Gabi fez o mesmo procedimento (2-a). Com isso, destacamos a mobilização das apreensões, sendo operatória mereológica, ao particionar as áreas dos quadrados; posicional, ao girar as peças para construir as áreas reduzidas; discursiva, ao relacionar o enunciado da redução com a figura; a perceptiva de formas e a sequencial, ao estruturar outro quadrado com as peças do tangram e com a régua.

Nesta tarefa, a representação figural icônica tem maior ênfase por possibilitar a visão das reduções e das operações figurais, a partir de tratamentos, ao particionar e decompor figuras, ao reduzir as áreas (4-c, 4-d) dos quadrados. Também, podemos perceber mobilização e reconhecimento de números racionais na representação fracionária, decimal e percentual. Em síntese, constatamos que a interpretação operador foi compreendida como uma composição, pois realizaram sucessivas reduções sobre as áreas dos quadrados anteriores (4-c, 4-e).

Quanto a conversão da representação percentual para a fracionária percebemos em 4-c, o reconhecimento imediato da representação percentual de $50 \%$ como sendo a metade, ou seja,. Sendo visível que esta representação percentual é usual para a turma. Em contra partida, a conversão da representação fracionária para decimal (4-f) observamos dúvidas em relação aos procedimentos do algoritmo e a falta de compreensão sobre o significado da divisão ao interpretar números racionais como quociente, fazendo-se necessária a abordagem também desta interpretação.

Durante a dinamização da Tarefa 4 tivemos maior ênfase em três sinais relacionados as representações e a transformação possibilitada pela interpretação operador, ligados com a atividade de formação. Sendo o sinal da palavra "diminuir" ou "reduzir" para indicar a redução das áreas, o sinal de "porcentagem", adaptado de Capovilla e Raphael (2008) devido a variação regional de Santa Maria, e a "vírgula", ao mencionarmos a representação decimal (Figura 9).

Figura 9 - Sinais convencionados na Tarefa 4

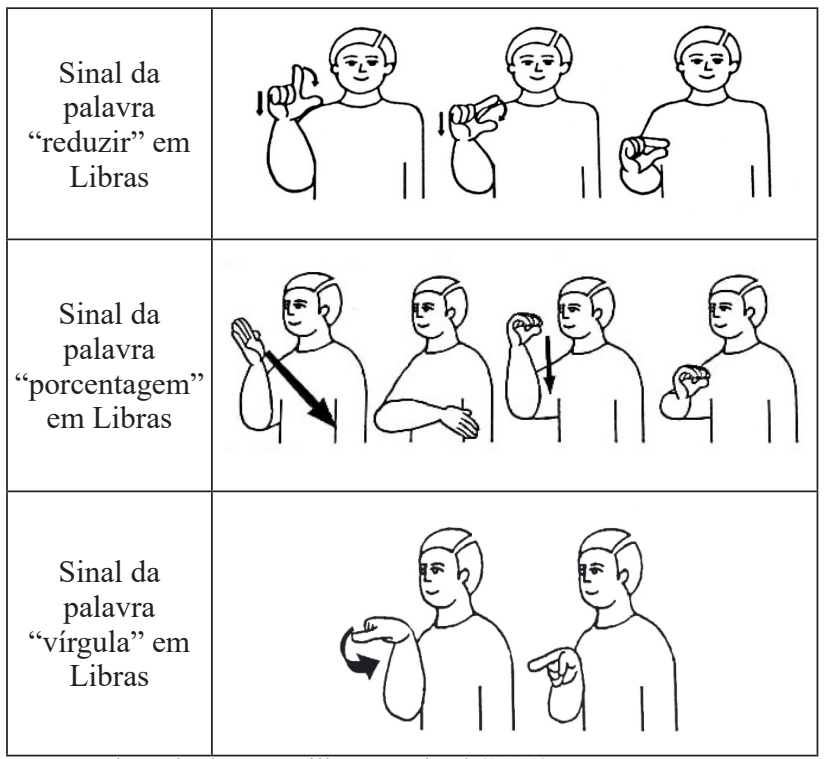

Fonte: Adaptado de Capovilla \& Raphael (2008).

\section{Conclusão}

A partir dos resultados apresentados destacamos o repertório linguístico dxs estudantes referentes aos conceitos/ conteúdos matemáticos, pois foi preciso convencionar sinais 
para as formas geométricas das peças do tangram e para alguns conceitos/conteúdos, no decorrer da dinamização da sequência.

Dessa maneira, concebemos que outros estudos devem ser realizados dando maior ênfase para a primeira língua natural dxs estudantes, isto é, a língua de sinais, apresentando o enunciado não somente no registro escrito em português, com intuito de valorizar e promover autonomia com relação a leitura e a escrita.

Por fim, vale ressaltar que presente trabalho faz parte de uma dissertação de mestrado desenvolvida no Programa de Pós-Graduação em Educação Matemática e Ensino de Física da Universidade Federal de Santa Maria, vinculado ao EMgep/ UFSM (Educação Matemática: grupo de estudos e pesquisas) e contou com apoio da Coordenação de Aperfeiçoamento de Pessoal de Nível Superior pelo financiamento 001.

\section{Referências}

Bardin, L. (2011). Análise de Conteúdo. Lisboa: Edições 70.

Beras, J. J., \& Lunardi-Lazzarin, M. L. (2018). Produções culturais surdas no contexto da educação bilingue. Revista Brasileira de Iniciação Científica. Itapetininga, 4 (5), 152-62.

Brasil. (2005). Decreto n. 5.626, de 22 de dezembro de 2005. Regulamenta a Lei n. 10.436 de 24 de abril de 2002, que dispõe sobre a Língua Brasileira de Sinais, e o art. 18 da Lei n. 10.098. Diário Oficial da União. Brasília.

Brasil. (2002). Lei $\mathrm{n}^{\mathrm{o}} 10.436$, de 24 de abril de 2002. Dispõe sobre a Língua Brasileira de Sinais - Libras e dá outras providências. Diário Oficial da União. Brasília.

Brasil. (2008). Ministério da Educação. Secretaria de Educação Especial. Política Nacional de Educação Especial na Perspectiva Inclusiva. Brasília: MEC/SEESP.

Brasil. (2014). Ministério da Educação. Secretaria da Educação Continuada, Alfabetização, Diversidade e Inclusão. Relatório sobre a Política Linguística de Educação Bilingue - Língua Brasileira de Sinais e Língua Portuguesa. Brasília: MEC/ SECADI.

Brasil. (2018a). Ministério da Educação. Secretaria de Educação Média e Tecnológica. Base Nacional Comum Curricular (Educação Infantil e Ensino Fundamental). Brasília: MEC.

Brasil. (2018b). Ministério da Educação. Secretaria de Educação Média e Tecnológica. Base Nacional Comum Curricular (Ensino Médio). Brasília: MEC.

Campos, T.M.M., \& Silva, A.F.G. (2009). Conhecimento profissional docente de professoras das séries iniciais da Educação Básica acerca da equivalência de números racionais na representação fracionária em um processo de formação continuada. Revemat, 4 (1), 114-27.

Campos, T.M.M., Magina, S., \& Nunes, T. (2006). O professor polivalente e a fração: conceitos e estratégias de ensino. Educação Matemática em Pesquisa, 8 (1), 125-136.

Capovilla, F.C., \& Raphael, W. D. (2008). Dicionário enciclopédico ilustrado trilíngue da Língua de Sinais Brasileira. São Paulo: USP.

Coutinho, M.D.M.C. (2015). A constituição de saberes num contexto de educação bilíngue para surdos em aulas de matemática numa perspectiva de letramento. 268 p. Tese (Doutorado em Educação) - Universidade Estadual de
Campinas, Campinas.

Duval, R. (2003). Registros de representações semióticas e funcionamento cognitivo da compreensão em matemática. In: S.D.A., Machado. Aprendizagem em matemática - registros de representação semiótica. Campinas: Papirus.

Duval, R. (2011). Ver e ensinar a matemática de outra forma: entrar no modo matemático de pensar: os registros de representação semiótica. São Paulo: PROEM.

Duval, R. (2012a). Abordagem cognitiva de problemas de geometria em termos de congruência. Tradução: Méricles Thadeu Moretti. Revemat, 7 (1), 118-38.

Duval, R. (2012b). Registro de representações semióticas de funcionamento cognitivo do pensamento. Revemat, 7 (2), 266-297.

Escola Estadual. (2018). Secretária do Estado da Educação. Projeto Político Pedagógico. Santa Maria.

Feneis. (1999). Federação Nacional de Educação e Integração dos Surdos. A educação que nós surdos queremos. Documento elaborado pela comunidade surda a partir do pré- congresso ao V Congresso Latino Americano de Educação Bilíngue para Surdos, realizado em Porto Alegre/RS, no salão de atos da reitoria da UFRGS, nos dias 20 a 24 de abril de 1999.

Frizzarini, S.T. (2014). Estudo dos registros de representação semiótica: implicações no ensino a aprendizagem da álgebra para alunos surdos fluentes em língua de sinais. 288 p. Tese (Doutorado em Educação para a Ciência e Matemática) Universidade Estadual de Maringá, Maringá.

Guerreiro, H.G., Serrazina, L., \& Ponte, J.P. (2018). Uma trajetória na aprendizagem dos números racionais através da percentagem. Educação Matemática Pesquisa, 20 (1), 35984.

Guimarães, T. S. (2017). Uma análise das representações semióticas mobilizadas em atividades sobre as interpretações do número racional com Frac-Soma 235 no Ensino Médio. 85 p. Trabalho de Conclusão de Curso (Licenciatura em Matemática) - Universidade Federal de Santa Maria, Santa Maria.

Guimarães, T. S., \& Mariani, R. C. P. (2018). Os registros de representações semióticas em atividades sobre a interpretação medida do número racional no Ensino Médio utilizando FracSoma 235. In: Anais do XV Encontro Gaúcho de Educação Matemática, VI Escola de Inverno de Educação Matemática, $4^{\circ}$ Encontro Nacional do PIBID Matemática. Santa Maria, RS, Brasil.

Kipper, D. (2015). Práticas matemáticas visuais produzidas por alunos surdos: entre números, letras e sinais. 156 p. Dissertação (Mestrado em Educação) - Universidade de Santa Cruz do Sul, Santa Cruz do Sul.

Lamon, S. J. (2007). Rational Numbers and Proportional Reasoning: Toward a Theoretical Framework for Research. In: LESTER, F. K. (org.). Second Handbook of Research on Mathematics Teaching and Learning: a Project of the National Council of Teachers of Mathematics. Charlotte: IAP/NCTM.

Lamon, S. J. (2012). Teaching fractions and ratios for understanding: Essential contente knowledge and instructional strategies for teachers. New York: Routledge.

Lemes, D. C. M. (2014). Ensino de Matemática no contexto da LIBRAS: prática e reflexões. 118 p. Dissertação (Mestrado em Ensino de Ciências e Matemática) - Universidade Luterana do Brasil, Canoas. 
Lorenzato, S. (2006). Laboratório de ensino de matemática e materiais didáticos manipuláveis. In: S., Lorenzato. $O$ laboratório de ensino de matemática na formação de professores. Campinas: Autores Associados.

Lüdke, M., \& André, M. (1986). Pesquisa em educação: abordagens qualitativas. São Paulo: EPU.

Moreira, P. C., \& Ferreira, M.C.C. (2008). A teoria dos subconstrutos e o número racional como operador das estruturas algébricas às cognitivas. Bolema, 21 (31), 103-127.

Morgado, A.S., Santos, R.S., \& Takinaga, S.S. (2016). Sugestão de alguns materiais para o ensino e aprendizagem para inclusão. In: A.L. Manrique, M.C.S.A, Maranhão, \& G.E, Moreira. Desafio da Educação Matemática Inclusiva: práticas. São Paulo: Livraria da Física.

Nascimento, L.S.A. (2014). Literatura infantil e alfabetização matemática: Construção de sentido na leitura de Enunciados matemáticos por crianças surdas dos anos iniciais do ensino fundamental. 143 p. Dissertação (Mestrado em Educação em Ciências e Matemática) - Instituto Federal do Espírito Santo, Vitória.

Neves, M.J.B. (2011). A Comunicação em Matemática na sala de aula: obstáculos de natureza metodológica na educação de alunos surdos. 131 p. Dissertação (Mestrado em Ciências e Matemáticas) - Universidade Federal do Pará, Belém.

Quadros, R.M. (1997). Educação de Surdos: a aquisição da linguagem. Porto Alegre: Artmed.

Santos, C.H., \& Imenes, L.M. (1987). Tangram: um antigo jogo chinês nas aulas de matemática. Revista do Ensino de Ciências, (18), 42-49.

Santos, M C.C. (2015). Investigação matemática em sala de aula: uma proposta para a inclusão do aluno surdo no ensino regular. 154 p. Dissertação (Mestrado em Educação para Ciências e Matemática) - Instituto Federal de Educação, Ciência e Tecnologia de Goiás, Jataí.

Silva, E. L. (2014). Luz, câmera, ação: adaptando uma teleaula de frações para o público surdo. 162 p. Dissertação (Mestrado em Educação Matemática) - Universidade Anhanguera de São Paulo, São Paulo.

Silva, E. L., \& Assis, C. (2013). O que falta no ensino de números racionais para alunos surdos? In: Anais do XI Encontro Nacional de Educação Matemática: Retrospectivas e Perspectivas, Curitiba, PR, Brasil.

Silva, M.J.F., \& Almouloud, S.A. (2018). Números racionais: concepções, representações e situações. In: G.P., Oliveira. Educação Matemática epistemologia, didática e tecnologia. São Paulo: Livraria da física.

Soares, M.A.S. (2016). Proporcionalidade um conceito formador e unificador da Matemática: uma análise de materiais que expressam fases do currículo da Educação Básica. Tese (Doutorado em Educação nas Ciências) - Universidade Regional do Noroeste do Estado do Rio Grande do Sul, Ijuí, RS.

Souza, F.R. (2010). Exploração de frações equivalentes por alunos surdos: uma investigação das contribuições da musicalcolorida. 166 p. Dissertação (Mestrado em Educação Matemática) - Universidade Anhanguera de São Paulo, São Paulo, SP.

Souza, L.J. (2016). Representações do conjunto dos números reais mobilizadas por alunos do CTISM/UFSM com o Tangram. Santa Maria: Universidade Federal de Santa Maria. 